University of Zurich

Department of Economics

Working Paper Series

ISSN 1664-7041 (print)

ISSN1664-705X(online)

Working Paper No. 24

\title{
The Coexistence of Commodity Money and Fiat Money
}

\author{
Olivier Ledoit and Sébastien Lotz
}

August 2011 


\title{
The Coexistence of Commodity Money and Fiat Money
}

\author{
Olivier Ledoit* Sébastien Lotz ${ }^{\dagger}$
}

August 31, 2011

\begin{abstract}
In reaction to the monetary turmoil created by the financial crisis of September 2008, both legislative and constitutional reforms have been proposed in different Countries to introduce Commodity Money alongside existing National Fiat Currency. A thorough evaluation of the Economic consequences of these new proposals is warranted. This paper surveys some of the existing knowledge in Monetary and Financial Economics for the purpose of answering the significant Economic questions raised by these new political initiatives.
\end{abstract}

\section{Introduction}

Recently, political representatives of various Countries and States have introduced proposals to make Commodity Money coexist with Fiat Money within current Monetary Systems. In Malaysia, on August 12, 2010, Kelantan — a State of the Malaysian Federation — introduced the Gold Dinar and the Silver Dirham as parallel currencies alongside the Malaysian Ringgit. Similarly, in the US, on March 25, 2011, Utah Governor Gary Herbert signed into law a bill recognizing not one but two (Gold and Silver) Commodity Monies as legal tender for all transactions conducted within the State of Utah - in parallel with the U.S. Dollar. The bill legalizes currency competition in Utah as the Gold and Silver coins may be used, and accepted voluntarily, as an alternative to the Dollar. Within the U.S., a dozen other States are considering similar legislation. In Switzerland, on March 9, 2011, a National Councillor introduced in Parliament an initiative to institute the "Gold Franc". A partial text of this official proposal is translated hereunder:

${ }^{*}$ Corresponding Author. Economics Department, Zurich University, Switzerland. olivier.ledoit@econ.uzh.ch

${ }^{\dagger}$ Laboratoire d'Economie Moderne, Université Panthéon-Assas-Paris 2, France. sebastien.lotz@u-paris2.fr 
The Confederation establishes an official Gold Franc with a set of coins of different denominations, each one containing a fixed amount of Gold. It regulates the criteria granted to establishments authorized to mint these coins. Additionally, the minting of Gold Franc coins is non-taxable. ${ }^{1}$

Review of this proposal reveals that Fiat and Commodity Money (Gold) may potentially compete as a medium of exchange in Switzerland. Moreover, we believe that the exchange rate of the Gold Franc relative to the Swiss Franc would not be set by the Government but would float freely according to supply and demand of Gold in the market (as in Utah, and Kelantan).

These political initiatives intended to facilitate the monetization of Gold in parallel with existing Fiat Money raise a number of interesting Economic questions:

1. If Commodity Money coexists in a Country with Fiat Money, will one of them eventually oust the other, or can they simultanously survive in the long run?

2. Is it in the best interest (welfare-enhancing) to monetize a Commodity?

3. How to solve the "big problem of small change"? Meaning that the cost of minting Gold coins in small denominations (down to 0.001 gram) is prohibitively expensive given current technology.

4. Is such an initiative likely to be successful in Countries dealing with either high or lowinflation?

5. If a Commodity Money is introduced in a Country where Fiat Money is internationally recognized as a "safe-haven currency", will this subsequently reduce capital flow into the National Fiat Money in times of crisis?

The intent of this paper is to review and analyze the existing state of knowledge within Monetary Economics to answer these five important questions. The benchmark of our analysis will be the Swiss proposal because of its simplicity, as well as the fact that it is based on a National Policy instead of a local one.

\footnotetext{
${ }^{1}$ It is worth noting that the purchase and sale of Gold is not subject to taxes (such as value-added tax or capital gains tax) under current Swiss law.
} 


\section{Coexistence}

A medium of exchange is an object that is accepted in trade not to be used for production or consumption, but to be traded later for something else that will be used for such purposes. When a Commodity serves as a medium of exchange, it is referred to as Commodity Money. When an object with no intrinsic value serves as a medium of exchange, it is referred to as Fiat Money. Fiat money has value simply because agents believe that it will. It is an endogenous property of money - its liquidity - that gives it value.

In Monetary Economics, "search theory" provides a framework within which to model the frictions that can lead to money having a useful role as a medium of exchange. As stressed by Kiyotaki and Wright (1989), "different objects have different intrinsic properties, making them more or less natural candidates for the role of money. These properties notwithstanding, a critical factor in determining if an object can serve as a medium of exchange is whether or not agents believe that it will. In other words, the use of money necessarily involves strategic elements, and certain aspects of social custom."

In their first model with Commodities, Kiyotaki and Wright (1989) illustrate the existence of a "fundamental" equilibrium such that agents always prefer a lower-storage-cost Commodity to a higher-storage-cost Commodity as a medium of exchange. They demonstrate the existence of a "speculative" equilibrium such that agents sometimes trade a lower-storage-cost Commodity for a higher-storage-cost Commodity, not because they want to consume it, but because they believe they will trade it later for another Commodity they want to consume. In this case, perhaps surprisingly, the least storable goods serve as Commodity Money while the most storable goods do not. These two different types of equilibrium prove that « extrinsic beliefs », or self-fulfilling prophecies, may be as important as « intrinsic properties » in determining which object may serve as a medium of exchange.

Extending their model to Fiat Money, the two authors show that both Commodities and Fiat Money may circulate in the economy, but Fiat Money is the only general medium of exchange in the sense that nobody refuses to trade goods with Fiat Money. They show existence of a fundamental equilibrium such that agents use the lower-storage-cost Commodity as a medium of exchange in parallel with Fiat Money, and a speculative equilibrium such that some agents use the lower- and higher-storage-cost Commodity as a medium of exchange in parallel with Fiat Money. If we think of storage costs as negative instantaneous rates of return while holding an asset, we have here an example of an object (a Commodity) being used as a medium of exchange in spite of the fact that it 
is dominated in rate of return by another object (another Commodity with better properties, or Fiat Money). Multiplicity of equilibria is of interest because it implies that a Commodity Money may be determined by more than fundamental consideration, like storage costs or other intrinsic properties. The Commodity Money model makes it even more clear that there is a tension between fundamental properties of assets and endogenous liquidity when it comes to determining the equilibrium medium of exchange.

At the opposite end of the spectrum, Kiyotaki and Wright (1991) show that it is possible to have equilibria where rational agents use Fiat Money as a medium of exchange even when Commodities have a greater interest rate or risk-free yield. In the same vein, Kiyotaki and Wright (1993) show that a high return asset may be less acceptable or less liquid than a low-return asset, or that both assets may be universally accepted, even though one is more dominant in rate of return than the other.

From the works of Kiyotaki and Wright, we believe the answer to the primary question is the following: Commodity Money, like Gold, can coexist in the same Country alongside Fiat Money, even though its storage or transaction costs - and rate of return - may be higher, and its use may never be as widespread as that of Fiat Money.

\section{Welfare}

The primary objective of the Swiss parliamentary initiative is clear: to make Gold become Commodity Money if people want it, i.e. to monetize Gold. This is done by developing a legislative framework where Gold coins can legally be bought, sold, and minted (and presumably melted) taxfree. Standardization of Gold coins and certification of Gold contents by a trusted authority are important also as it should reduce cognitive costs as well as verification costs. Furthermore, if one Gold Franc is defined as 0.1 gram of gold, which is a very small quantity, then minting coins of 1 , 2, 5, 10, 20 and 50 Gold Francs (containing respectively 0.1 gram, 0.2 gram, 0.5 gram, 1 gram, 2 grams and 5 grams of Gold) would greatly enhance the divisibility of Gold, which is the primary, and required characteristic of any object that may be used as money.

Gold has intrinsic value, which Fiat Money does not. However, Gold can be considered either as having a higher transaction or storage cost than Fiat Money, or having a higher rate of return. Kiyotaki and Wright (1991) mention that "even if Fiat Money is endowed with properties making it a less than ideal asset (e.g., a relatively low rate of return) or a less than ideal medium of exchange (e.g., relatively high transaction cost), it can continue to circulate and play a role in facilitating trade 
and improving welfare. Of course, if the intrinsic properties of Fiat Money become too unfavourable, then naturally it will not circulate in equilibrium." What is true with Fiat Money is also true with Commodity Money. Therefore, to paraphrase Kiyotaki and Wright (1991), even though Commodity Money has relatively high transaction or storage costs, it can circulate and play a role in facilating trade and improving welfare. Identically, if Gold has a higher return than Fiat Money, the use of this Commodity as Money may generate an increase in welfare if it circulates in parallel with Fiat Money.

If we believe that the transaction and storage costs of Gold have decreased in current modern economies, it means that Commodity Money in form of Gold coins may have more chances to be used as Money, even in an economy where Fiat Money with zero transactions and storage costs circulates. Indeed, within the Kiyotaki and Wright (1989) model, the reduction in the "storage" cost of one Commodity (Gold, for example) can lead to the existence of an equilibrium where this Commodity, that was not used as a medium of exchange because of its high cost, starts to circulate as a means of payment. Additionally, in this model, the reduction in the storage cost or equivalently the increase in the rate of return — of the circulating Currency enhances welfare, i.e. benefit Society.

We can answer the second question raised in the Introduction: according to the Kiyotaki and Wright (1989) model, the monetization of a Commodity - like Gold — with a higher return than Fiat Money, or the decrease in storage costs of Commodity Money can be Pareto-improving, meaning good for agents in the economy.

\section{Small denominations}

There is no technological difficulty in minting a coin containing two or five grams of pure Gold, which corresponds to 20 or 50 Gold Francs under the Swiss proposal. Minting costs are minimal when the number of coins minted is large. Since the Swiss proposal clearly stipulates that Gold Francs would be minted by Commercial Banks, the Banks would be allowed to put their brand name and/or logo on one side of the coin. The marketing benefits from having the bank logo in every citizen's wallet would clearly cover any minting costs, so these coins could be sold at par value with the market value of their weight in Gold.

The smaller the coin denominations, the more problematic the production costs become. Eventually, the market will decide, and there will be limited production of one Gold Francs (0.1 gram) or twenty Gold Francs (2 grams), or perhaps something in between, where banks will refuse to mint 
lower-denomination coins, and sell them at par value. This is actually an age-old problem with Commodity Money, and Sargent and Velde (2002) illustrate that shortages of small coins have occured repeatedly throughout history, severely disrupting the smooth functioning of economies that previously used Commodity Money.

What is emphatically not a solution is to mint small-denomination coins using a metal less precious than Gold, such as Silver. Sargent and Velde (2002) illustrate that failure occurs eventually since these coins will disappear from circulation if market forces push the commodity value of Silver too high relative to that of Gold.

The primary solutions to this problem that are consistent with current Economic thinking are listed below:

Technology Progress in minting technology could allow manufacturers to produce coins containing very small quantities of Gold, even as low as 0.1 gram, at reasonable cost. Such technology does not currently exist yet, but given sufficient economic incentives, it may be invented. For example, one can imagine a coin consisting of two discs of transparent plastic encasing a visible nugget of Gold. However, this would not "look like a coin"... An important lesson of Kiyotaki and Wright (1989) is that monetary equilibria are self-fulfilling, in the sense that people only recognize a medium of exchange that everyone else recognizes.

Fiat Money Since Fiat Money would continue to circulate, it could be the medium of exchange used for all smaller transactions. For example, if you pay with a 50 Gold Franc coin, the supermarket cashier could give you change in Swiss Francs. The disadvantage is that you would always end up with Fiat Money, and you would be exposed (on a small scale) to market-driven fluctuations in the exchange rate between Fiat Money and Commodity Money (Gold).

Tokens What Sargent and Velde (2002) call the "standard formula" is for banks to produce tokens containing no precious metals, yet exchangeable at a pre-determined rate for the 50 Gold Franc coin, for example. Under such a system, the 1 Gold Franc coin would contain no Gold at all, however 50 of them could be freely exchanged for one coin containing 5 grams of pure Gold. Sargent and Velde (2002) illustrate that this is a sustainable solution. Some government auditing would be required to ensure that the number of tokens issued by a bank is covered by the number of 50 Gold Franc coins contained in its vaults, so that in the event of a run on the banks tokens, all customers could be reimbursed with physical Gold Francs without 
causing bankruptcy.

Debit Cards An economic equivalent, yet technically a more modern variation on this idea, would be for banks to offer accounts denominated in Gold Francs, and debit cards tied to these accounts. Customers could settle most transactions electronically using these cards. At any point in time, a customer could increase the balance on his Gold Franc account by physically depositing a 50 Gold Franc coin into the bank, or decrease it by physically withdrawing a 50 Gold Franc coin. Similarly, government auditing would be necessary to ensure that Gold Franc account balances are 100\% backed by Gold Franc coins physically held in the banks vaults to avoid the possibility of shortfalls. Cavalcanti and Wallace (1999) illustrate that the same degree of confidence can be achieved without government auditing, as long as there is public disclosure of the trading history of the banking sector.

The conclusion of this analysis is that there are means for the liquidity benefits of small denominations to be preserved when a Commodity Money is introduced simultaneously with an established Fiat Money within a modern regulated banking system.

\section{$5 \quad$ Monetary Policy}

One concern is that the introduction of a Commodity Money could restrict the ability of the Central Bank to pilot the economy by controlling Fiat Money. Indeed, if Central Bank policy was too loose, the rate of return of Fiat Money would decrease, leading to inflation. This would create an increase in the storage - or holding - cost of Fiat Money, and consequently a decrease in demand. Thus, conceivably, if monetary policy was too expansionary, the pre-eminence of Fiat Money as a medium of exchange could be threatened by a decline in its attractiveness relative to Commodity Money.

The first element to be considered on this question is posed by Aiyagari and Wallace (1992). They illustrate that Fiat Money can still be used in steady-state equilibrium even if it is costly to hold. This means that there is considerable margin of maneuver for the Central Bank to conduct Monetary Policy, without having to be concerned that Fiat Money may decline into unpopularity. However, Aiyagari and Wallace (1992) contend that there must eventually be a limit to how much Fiat Money inflation the Central Bank can withstand before Commodity Money begins to take precedence.

The same insight appears in a more recent paper by Camera, Craig and Waller (2004), where two currencies, one safe and one risky - meaning inflationary - compete in a decentralized trading 
environment. Their setup is slightly different from ours, because they study the coexistence of a local Fiat Money with a foreign Fiat Money (such as the Dollar), instead of studying the coexistence of a local Fiat Money simultaneously with Commodity Money. Therefore, in their model, the role that we would wish to be played by Commodity Money is instead played by the Dollar. Their analysis suggests that:

a poorly functioning economy with risky currency is prone to dollarization. Thus our analysis is consistent with the view that the local currency sustains internal trade if the purchasing power risk is kept very low, but once that risk gets very high substantial currency substitution kicks in. The normative aspect of our study is that a low dollarized economy can avoid becoming highly dollarized by implementing policies aimed at reducing currency risk and improving the trading environment so that the economy functions well. At the same time our results serve as a warning that dollarization will be unavoidable if currency risk is not kept under control.

Since the analogy to dollarization in our setup is the substitution of Fiat Money by Commodity Money, Central Banks implementing rational policies consistent with low inflation have nothing to fear from the introduction of Commodity Money. However, Central Banks that are tempted to adopt inflationary policies will find their monetary power reduced as people will start using Commodity Money as a substitute for Fiat Money. Therefore, introducing Commodity Money alongside Fiat Money is politically easier in countries where Central Banks pursue low-to-moderate inflationary policies. On the countrary, in countries where Central Banks pursue inflationary or hyper-inflationary policies - i.e., in countries where Commodity Money may supplant Fiat Money - it is likely that the Central Bank will do everything in its power to oppose the introduction of Commodity Money.

To sum-up, since the introduction of Commodity Money requires a change in the Constitution, it might be judicious to push for such a measure while inflation is low; if inflation surge, such a move will become more and more difficult to implement.

\section{Safe Haven}

Ranaldo and Söderlind (2010) contend empirically that the Swiss Franc is a "safe haven" currency (i.e., it tends to appreciate in times of crisis). Unfortunately, this implies that the exchange rate between the Swiss Franc and currencies of Switzerland's main trading partners, notably the Euro, 
can demonstrate exacerbated volatility due to the flow of international capital in search of safety, which in turn tends to have a disrupting influence on the Swiss economy. In January 2010, the Swiss National Bank (SNB) stated that it would fight any "excessive" appreciation of the Swiss Franc against the Euro. The SNB foreign currency reserves more than quadrupled to SFr230 billion between the financial crisis and June 2010, with the total increasing by SFr135 billion since December 2009 alone. Fighting against Swiss Franc appreciation caused the SNB to post a consolidated loss of SFr19.17 billion for 2010. This is generally perceived in Switzerland as problematic, and raises the question of whether the introduction of the Gold Franc could help alleviate this problem.

Baur and McDermott (2010), and Baur and Lucey (2010) demonstrate empirically that Gold is also a "safe haven" asset. This suggests that international capital seeking safety has other outlets than the Swiss Franc: they can also seek out Gold. The existence of Gold as a "safe haven" has already taken some of the pressure off the Swiss Franc, subsequently alleviating the exchange rate problem of the Swiss economy in times of crisis. The question is: Would the introduction of the Gold Franc make Gold increasingly more of a safe asset? If the answer was yes, then we could assume that the introduction of the Gold Franc would help alleviate exchange rate problems in Switzerland.

In answering this question, we must understand why Gold is in demand. It is because of its physical qualities: it is useful in jewellery, dentistry and certain industrial applications. An important part of the demand for Gold stems also from the perception that there is some connection between Gold and Money.

Most economists believe that there is no more reason to think of Gold as Money than there is to think of sea shells as Money. Keynes (1924) famously described the early XX ${ }^{\text {th }}$ century Gold Standard as a "barbarous relic". Decades of economists educating the general public about this topic have had only moderate impact in reducing this perception. Certainly education has had some impact, but it has not succeeded totally, and there is no indication that it will be able to do so within the foreseeable future.

From a pragmatic point of view, the question is: What to do about these perceptions? Again, the two options are to: 1) fight against them in the hope (but with no guarantee) that they will disappear in the near future, or 2) take advantage of them. A typical example of the second option is the declaration by then-U.S. Treasury Secretary James Baker that: "President [Reagan] and I are not prepared to take that step [selling the Gold in Fort Knox] because it would undercut confidence here and abroad based on the widespread belief that the Gold reserve is the foundation of our financial system". James Baker utilized the public perception that there is some connection between Gold 
and Money to support the U.S. Dollar, which was one of his objectives at that time. In 2011, Mary J. Miller from President Obama's Treasury Department re-used the exact same argument.

The Achilles' heel of the perception of Gold as somehow connected with Money is that it is currently founded on nothing tangible. Indeed, it is founded on history, culture and psychology, but not on reality: There is no supermarket in the world where you can pay your groceries with Gold coins. In light of this, it is quite remarkable that Gold is also considered as a safe haven in spite of the fact that it is not currently used as Money in the world.

At the end, the question is whether there exists an opportunity for Swiss leaders to utilize this perception in order to alleviate their exchange rate problems. We believe that any tangible steps towards the monetization of Gold would reinforce its safe haven status, and take some of the pressure off the exchange rate of the Swiss Franc against the currencies of its major trading partners (especially the Euro) in times of crisis.

\section{Conclusion}

Legislative and constitutional reforms aimed at making a certain Commodity, like Gold, similar to Money raise several important questions that we have answered. First, Commodity Money can coexist alongside Fiat Money, as long as the Central Bank managing Fiat Money maintains a commitment to ward off the threat of hyper-inflation, and multiplicity of circulating currencies may enhance social welfare. Second, the combination of modern financial systems and modern minting technology should be able to prevent the periodic shortages of small change which historically handicapped Commodity Money. Third, in the specific case of Switzerland, an additional advantage is that monetizing Gold would make it more attractive as a safe haven currency, thereby reducing the recurrent problems caused by excessive appreciation of the Swiss Franc when there is a financial crisis. In summary, economic theory can support the introduction of Commodity Money simultaneously with Fiat Money. 


\section{References}

Aiyagari, S.R. and N. Wallace. 1992. "Fiat money in the Kiyotaki-Wright model." Economic Theory $2(4): 447-464$.

Baur, D.G. and B.M. Lucey. 2010. "Is gold a hedge or a safe haven? An analysis of stocks, bonds and gold." Financial Review 45(2):217-229.

Baur, D.G. and T.K. McDermott. 2010. "Is gold a safe haven? International evidence." Journal of Banking \& Finance 34(8):1886-1898.

Camera, G., B. Craig and C.J. Waller. 2004. "Currency competition in a fundamental model of money." Journal of International Economics 64(2):521-544.

Cavalcanti, R.O. and N. Wallace. 1999. "A Model of Private Bank-Note Issue." Review of Economic Dynamics 2(1):104-136.

Keynes, J.M. 1924. A tract on monetary reform. London: Macmillan.

Kiyotaki, N. and R. Wright. 1989. "On money as a medium of exchange." The Journal of Political Economy 97(4):927-954.

Kiyotaki, N. and R. Wright. 1991. "A contribution to the pure theory of money." Journal of Economic Theory 53(2):215-235.

Kiyotaki, N. and R. Wright. 1993. "A search-theoretic approach to monetary economics." American Economic Review 83(1):63-77.

Ranaldo, A. and P. Söderlind. 2010. "Safe Haven Currencies." Review of Finance 14(3):385.

Sargent, T.J. and F.R. Velde. 2002. The big problem of small change. Princeton Univ Press. 